\title{
Development of Rice Powdering Equipment Using a Shock Wave
}

\author{
Shigeru Tanaka ${ }^{1)}$, Hironori Maehara ${ }^{2)}$, Mikiya Matsuda ${ }^{3)}$, and Shigeru Itoh ${ }^{4)}$ \\ 1) Faculty of Engineering, Kumamoto University, 2-39-1 Kurokami, Kumamoto City, Kumamoto 860-8555, Japan \\ Fax: 81-96-342-3902, e-mail: tanaka@tech.eng.kumamoto-u.ac.jp \\ 2) Graduate School of Science and Technology, Kumamoto University, 2-39-1 Kurokami, Kumamoto City, Kumamoto 860-8555, \\ Japan \\ Fax: 81-96-342-3740, e-mail: maehara@shock.smrc.kumamoto-u.ac.jp \\ 3) Faculty of Engineering, Kumamoto University, 2-39-1 Kurokami, Kumamoto City, Kumamoto 860-8555, Japan \\ Fax:81-96-342-3696, e-mail: matsuda@tech.eng.kumamoto-u.ac.jp \\ 4) Shock Wave and Condensed Matter Research Center, Kumamoto University, 2-39-1 Kurokami, Kumamoto City, Kumamoto \\ 860-8555, Japan \\ Fax: 81-96-342-3299, e-mail: itoh@mech.kumamoto-u.ac.jp
}

\begin{abstract}
New technique of rice powdering was developed by using shock wave. Current charged in a condenser is discharged large-current instantaneously at between electrodes where is placed in water. Under water shock wave is generated from between the electrodes. Rice and titanium ball are put into polycarbonate bottle by half of the bottle, and the rice is separated from water by the bottle. The bottle contained the rice is loaded by under-water shock wave, the rice is accelerated to high velocity and collided with each other. The shock loaded process does not generate heat during powdering, because the process is finished momentary. Heat is generated in conventional process of rice powdering, and the heat lose flavor of rice. Potential flavor of rice is maintained and bactericide effect is expected by this technique. Recovered rice powder was evaluated by grain distribution.

Key words: rice powdering, condenser, large-current, under-water shock wave, vactericide
\end{abstract}

\section{INTRODUCTION}

Rice powder is flour milling and expected that development of new market and expansion of sell-through for consumption rise of domestic product or homegrown rice. Rice powder is made from Urchi rice or glutinous rice (an especially sticky variety). Conventional Uruchi rice has been made from inedible crashed rice as a source reagent, but in recent years the number of case using edible rice is tend to increase. Other source reagent rice are manufacturing rice, minimum access (MA) rice and spot goods liquidation rice. The manufacturing rice is mostly turned over by Japan Agriculture Cooperatives. It is possible to include the edible rice into acreage reduction by making the edible rice for the manufacturing rice. The manufacturing rice is relatively expensive compared with Uruchi rice, but the quality of it is same as edible rice's one. MA rice is imported rice from foreign country by complying with the agreement of WTO, and the amount of import is about 800,000 ton per year. The spot goods liquidation rice is turned over by incorporated association, and the usage is limited but the price is relatively low. After these rice are crashed in order to prevent diversion to edible rice, these rice are sold off. Rice powder is divided into Jyou-Shin powder and
Shira-Tama powder by the source of rice and method of processing.

For one year consumption of rice is decreased to nine million tons (recent year) from 13.41 million tons (fiscal year 1962) in Japan, and per capita consumption has decreased sharply to $61.4 \mathrm{~kg}$ (fiscal year 2005) from $118.3 \mathrm{~kg}$ (fiscal year 1962). The administration and the related group have worked to aim the consumption rise in such a situation. Only in a past Japanese-style confection product, it was difficult to expect the consumption rise. The expectation of rice for the consumption rise has risen by the technology's that mass-produces bread and the noodle, etc. having been established. The reason that did not spread for ten years or more was due to the price difference between rice and wheat. However, the international market of wheat rises greatly in recent years. The rice powder in domestic Japan came to be highlighted as a flour substitute. The Ministry of Agriculture, Forestry and Fisheries began to do the increased production support of the rice powder as a flour substitute due to sudden rise of the price of wheat. New law was approved in April, 2009. 
General process for making rice powder is shown as follow, 1) Washing rice, 2) Penetration water into rice, 3) Pre Drying, 4) Powdering by crushing roller, 5) Powdering by air draft crushing machine, 6) Drying. In this method, there are demerits which are energy consumption for drying and decreasing flavor of rice by generated heat during a drying process[1].

In this time, we developed rice powdering equipment using a shock wave. Shock wave can make apart rice easily. Because of momentary processing of shock wave, there is no heat generation. It is not necessary that washing by water and penetration water into rice. So, this technique can skip drying process. Detail of the equipment and recovered rice powder are shown in this paper.

\section{RICE POEDERING EQUIPMENT}

The equipment developed this time is classified into three general parts. They are condenser part, shock process part and control part. Fig. 1 shows the condenser part. There are four condensers which are connected each other in parallel. $100 \mathrm{~V}$ alternating current (AC) is raised up to $3.5 \mathrm{kV}$ by transformer and the $\mathrm{AC}$ is converted to direct current (DC) through the diode. The DC is charged into four condensers. Strength voltage and capacitance of the condenser are $4.5 \mathrm{kV}$ and $200 \mu \mathrm{F}$ respectively. Strength voltage probe (1000:1) is connected to positive terminal of the condenser. The charged voltage adjusted to $1 / 1000$ by the probe is displayed on a voltmeter. There are three switches in the part. They are a charge, a discharge and a neutralization switch. Air cylinders are applied for those switches mechanism, because of strong switching and safety. Especially in the discharge switch, large-current flows momentary when the switch is turned on. Fleshy cupper is applied for electrode of discharge switch. $20 \mathrm{k} \Omega$ discharge resistance is applied for condenser part circuit. It takes about 40 seconds to finish once operation which is a charge and a discharge.

Fig.2 shows schematic illustration of shock process part. Two electrodes are installed horizontally-opposed and they are placed through high-polymer material because metal material can't be used for holding the electrodes. These electrodes are surrounded in water. Cupper-tungsten is applied for electrode in order to withstand a repetitive discharge. The gap between the electrodes as shown in Fig. 2 is set up suitable distance which can generate under-water shock wave. The under-water shock wave is propagated through the water in the metal pipe. Rice and titanium ball are put into polycarbonate bottle by half of the bottle, and the rice is separated from water by the bottle. Titanium is harmlessness and it helps to crash the rice by collision with the rice and the ball. The bottle is put into the water as shown in Fig. 2 and applied shock load. Fig. 3 shows an appearance of the shock process part.

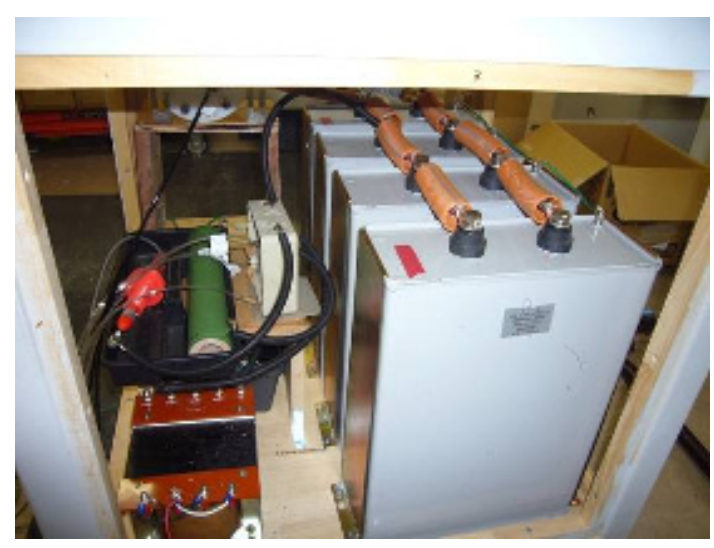

Fig. 1 Condenser part

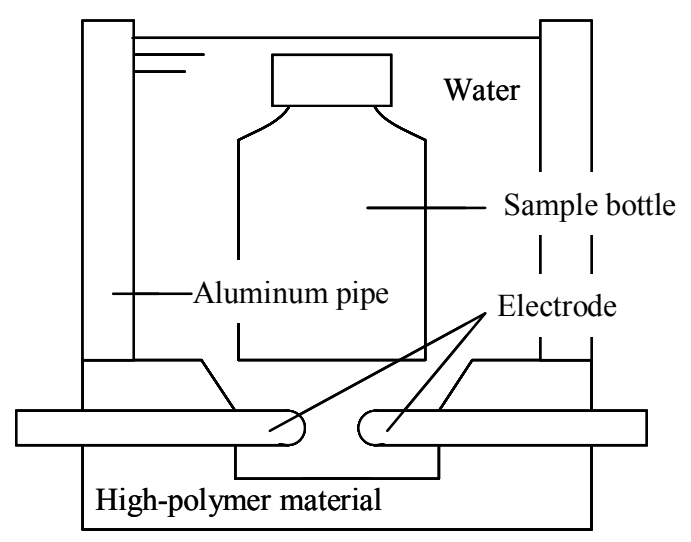

Fig. 2 Schematic illustration of shock process part set up

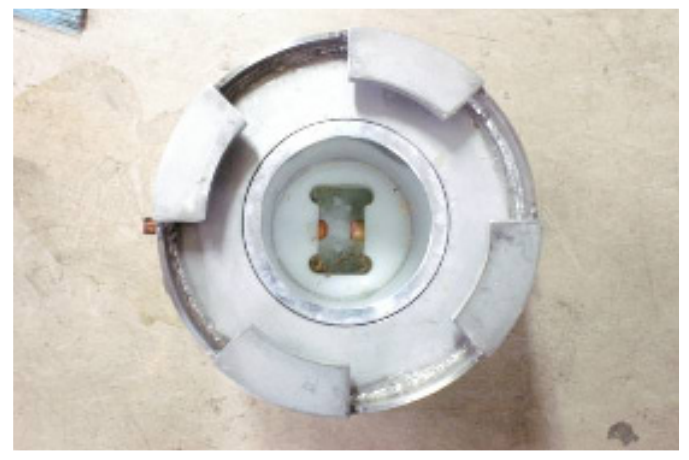

Fig. 3 Shock process part

Fig. 4 shows a control part. There are voltmeter for displaying $1 / 1000$ voltage of charged into condenser, three change valves (CHARGE, 
DISCHARGE, EARTH) for controlling the air cylinder and voltage inverter for charging.

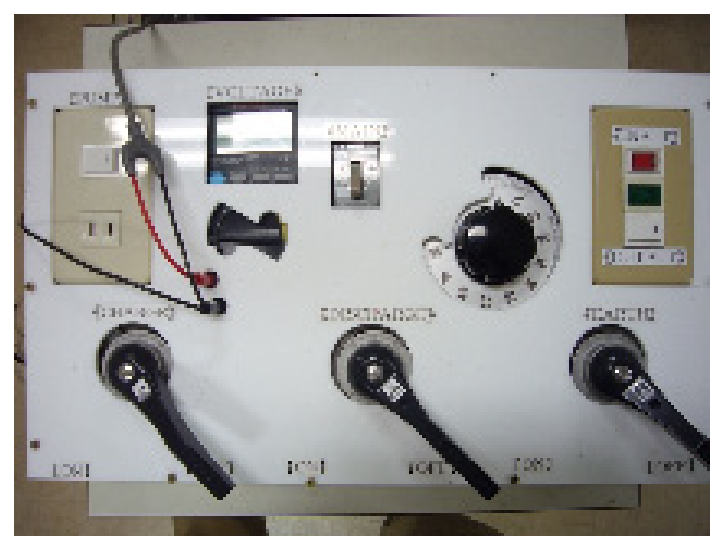

Fig. 4 Control part

\section{EXPERIMENT}

Rice applied for experiments was Akimasari which is high-yielding variety and edible rice. The rice is shown in Fig.5. Conventional rice used for rice powder is crashed in order to prevent diversion to edible rice, but there are not any cracks in the Akimasari particle. The moisture content of the rice was measured by leaving rice in the atmosphere of 135 degrees Celsius for 20 hours, and measuring the mass change. The result was $11.3 \%$. The rice was put into $250 \mathrm{cc}$ polycarbonate bottle with titanium balls. The bottle is half empty. The bottle included the rice and the titanium ball is shown in Fig. 6. The bottle secludes rice from water. The titanium balls help rice to crash. The diameter of the ball applied for experiments is $5 \mathrm{~mm}$ or $8 \mathrm{~mm}$, and it is harmlessness. Ball milling method is applied for powder crashing. In the case of usual ball milling process, using of the minor diameter ball is an effective means to obtain a fine powder. Moreover, balls should be larger than the powders in terms of crushing area when two balls collide[2]. In the bottle, there is a space where the rice and titanium balls can be moved through shock loading. When the shock wave passes through the rice and the titanium ball, they are accelerated to high velocity and are collided with each other. The discharge energy was $4.9 \mathrm{~J}$ when the charging voltage was $3.5 \mathrm{kV}$. Experimental conditions are shown in table 1 . Recovered rice powder was evaluated by grain size distribution.

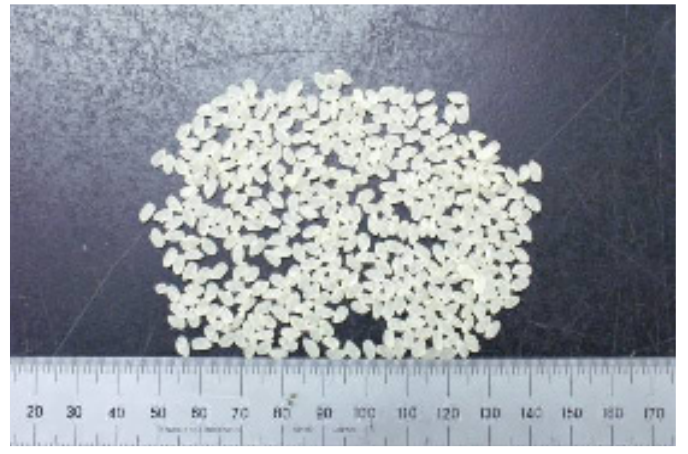

Fig. 5 Akimasari

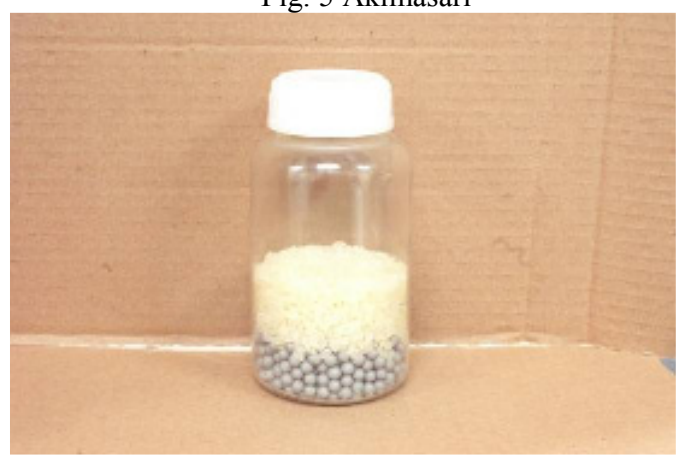

Fig. 6 Rice ant titanium ball in polycarbonate bottle

Table 1 Experimental conditions

\begin{tabular}{|c|c|c|c|c|}
\hline No. & $\begin{array}{c}\text { Mass of ofice } \\
(\mathrm{g})\end{array}$ & $\begin{array}{c}\text { Mass of oftanium ball } \\
(\mathrm{g}\end{array}$ & $\begin{array}{c}\text { Dimeter of thanium ball } \\
(\mathrm{mm})\end{array}$ & Shock process times \\
\hline 1 & 65 & 135 & 5 & 20 \\
\hline 2 & 65 & 135 & 8 & 20 \\
\hline
\end{tabular}

\section{RESULTS AND DISSUCATION}

The result of grain distribution is shown in table 2.

Result of grain size distribution is shown in table 2. The rice before shock applied can't pass through the mesh of $4.75 \mathrm{~mm} \times 4.75 \mathrm{~mm}$. In the case of applying smaller ball, grain size tended to decrease from the results. In the both experimental results, the rice powder in the range of $2360-4750 \mu \mathrm{m}$ is major. It is easy to consider that the rice powder in the range transmission to smaller range by more shock loading times. It should be noted that the No.1 rice powder in the range of $150-300 \mu \mathrm{m}$ is less than No.2. It is considered that the $5 \mathrm{~mm}$ titanium ball worked so well for the rice powder in the range.

Table 2 Result of grain size distribution 


\begin{tabular}{|c|c|c|c|}
\hline \multicolumn{2}{|c|}{} & \multicolumn{2}{c|}{ No. } \\
\cline { 2 - 4 } \multicolumn{1}{|c|}{} & $\begin{array}{c}1 \\
(\mathrm{~g})\end{array}$ & $\begin{array}{c}2 \\
(\mathrm{~g})\end{array}$ \\
\hline \multirow{4}{*}{} & Over 4750 & 0 & 0 \\
\cline { 2 - 4 } & $2360-4750$ & 5.12 & 9.34 \\
\cline { 2 - 4 } $\begin{array}{c}\text { Grain size } \\
(\mu \mathrm{m})\end{array}$ & $1180-2360$ & 23.86 & 28.02 \\
\cline { 2 - 4 } & $600-1180$ & 14.22 & 11.04 \\
\cline { 2 - 4 } & $300-600$ & 10.38 & 7.51 \\
\cline { 2 - 4 } & $150-300$ & 1.09 & 3.62 \\
\cline { 2 - 4 } & Less 150 & 8.62 & 4.67 \\
\hline
\end{tabular}

\section{CONCLUSIONS}

Rice powdering equipment using shock wave was developed. Tow difference size titanium ball was applied for experiments, and recovered rice powder was evaluated by grain size distribution. In the case of applying smaller ball, grain size tended to decrease. The $5 \mathrm{~mm}$ titanium ball worked so well for the rice powder in $150-300 \mu \mathrm{m}$ range. Optimum condition of ball effect is researched in future works.

\section{ACKNOWLEGDGMENT}

This research is supported by Ministry of Agriculture, Forestry and Fisheries of Japan.

\section{REFERENCE}

[1] K. Yamaguchi, "Okome Kakumei", Ed. by E. Kohori, Chigensya, Saitama, Japan (2008) pp. 168.

[2] S. Tashiro, H. Igarashi, The ceramic society of Japan, 98, 10, 1082 (1990)

(Received January 27, 2010; Accepted July 31, 2010) 